\title{
Identification and mapping of quantitative resistance to late blight (Phytophthora infestans) in Solanum habrochaites LA1777
}

\author{
Junming Li $\cdot$ Lei Liu $\cdot$ Yuling Bai $\cdot$ Richard Finkers • \\ Feng Wang $\cdot$ Yongchen Du $\cdot$ Yuhong Yang $\cdot$ Bingyan Xie $\cdot$ \\ Richard G. F. Visser · Adriaan W. van Heusden
}

Received: 19 November 2009/Accepted: 28 December 2010/Published online: 19 February 2011

(C) The Author(s) 2011. This article is published with open access at Springerlink.com

\begin{abstract}
Late blight (Phytophthora infestans) can have devastating effects on tomato production over the whole world. Most of the commercial cultivars of tomato, Solanum lycopersicum, are susceptible. Qualitative and quantitative resistance has been described in wild relatives of tomato. In general qualitative resistance can more easily be overcome by newly evolved isolates. Screening of three S. habrochaites accessions (LA1033, LA2099 and LA1777) through a whole plant assay showed that accession LA1777 had a good level of resistance to several isolates of $P$. infestans. To explore the potential in this wild species, an introgression line (IL) population of S. habrochaites LA1777 was used to screen individual chromosome regions of the wild species by a detached leaf assay. Two major isolates $\left(\mathrm{T}_{1,2}\right.$ and $\mathrm{T}_{1,2,4}$ ) were used and two parameters were measured: lesion size (LS), and disease incidence (DI). Substantial variation was observed between the individual lines. QTLs were identified for LS but not for DI.
\end{abstract}

J. Li (ه) · L. Liu · F. Wang · Y. Du · Y. Yang · B. Xie Institute of Vegetables and Flowers, Chinese Academy of Agricultural Sciences, No. 12 Zhongguancun Nandajie, Haidian District, Beijing 100081, China

e-mail: junmingli@mail.caas.net.cn

J. Li · Y. Bai - R. Finkers · R. G. F. Visser ·

A. W. van Heusden

Graduate School Experimental Plant Sciences,

Wageningen UR Plant Breeding, Wageningen University and Research Center, PO box 386, 6700 AJ Wageningen, The Netherlands
The presence of five QTLs derived from LA1777 (Rlbq4a, Rlbq4b, Rlbq7, Rlbq8 and Rlbq12) results in unambiguous higher levels of resistance. All QTLs co-localized with previously described QTLs from S. habrochaites LA2099 except QTL Rlbq4b, which is therefore a novel QTL.

Keywords Tomato $\cdot$ Late blight $\cdot$ Phytophthora infestans $\cdot$ Quantitative resistance $\cdot$ Solanum habrochaites $\cdot$ Introgression lines

\section{Introduction}

The oomycete Phytophthora infestans (Mont.) de Bary, the causal agent of late blight, is one of the most destructive pathogens of potato and tomato. Late blight causes serious yield and economic losses especially under favorable conditions for the pathogen (wet and cool temperatures) both in the open field as well as in non-heated greenhouses. The responsible pathogen is heterothallic and forms oospores with A1 and A2 mating types and has been found in different areas of the world (Gotoh et al. 2005). The co-existence of mating types and the sexual reproduction increase the chance of developing resistance to fungicides such as metalaxyl (Goodwin et al. 1998; Gotoh et al. 2005). In addition, the spread of the disease may be also initiated from spores present in the soil (Widmark et al. 2007). The genetic diversity, 
rapid evolution and the broader range of virulence factors have made this pathogen more and more aggressive (Drenth et al. 1995; Gotoh et al. 2005). Tomato plants can be completely destroyed in a few weeks despite the use of chemicals to control the infections (Jones et al. 1991).

The most effective and environmentally favorable way to prevent devastation of tomato plants by this pathogen is to incorporate natural resistance into cultivars. Two kinds of host plant resistance to $P$. infestans have been described in tomato (Labate et al. 2007). Firstly there is the qualitative or racespecific resistance. This resistance is based on " $R$ " genes, examples are $P h-1, P h-2, P h-3, P h-4$ and $P h-5$ which originate from the wild species $S$. pimpinellifolium and the position of these R-genes has been determined on chromosomes 7, 10, 9, 2 and 1, respectively (Chunwongse et al. 2002; Peirce 1971; Foolad et al. 2008; Kole et al. 2006; Moreau et al. 1998). However, these qualitative resistances are not durable due to the rapid evolution of compatible races of the pathogen. The first four genes have already been broken by newly evolved races of $P$. infestans (Kole et al.2006; Foolad et al. 2008) and the durability of the $P h-5$ gene is still a question. It is expected that combining or pyramiding several genes could provide a more durable resistance than deploying just a single one (Foolad et al. 2008).

The second type of resistance is quantitative resistance that is controlled by quantitative trait loci (QTLs). Quantitative resistance is often non racespecific and more durable than qualitative resistance governed by R-genes (Brun et al. 2010; Palloix et al. 2009; Robert et al. 2009). For resistance to late blight, research in potato has been since 1970 focusing on introducing quantitative resistance (Wastie 1991), in spite of the fact that already eleven single R-genes were known. In tomato, $S$. habrochaites is believed to be a potential donor for high levels of quantitative resistance (Brouwer et al. 2004). Five to six consistent QTLs have been identified in two $\mathrm{BC}_{1}$ populations derived from $S$. habrochaites LA2099 and lines with all four major QTLs introgressed were more resistant to $P$. infestans in different environments. Recently, one QTL was identified from the wild species S. pennellii LA716 (Smart et al. 2007). These identified QTLs could be explored in tomato breeding for quantitative and non race-specific resistance to $P$. infestans.
An introgression line population (IL) has several advantages over segregating populations such as $\mathrm{F}_{2}$ and $\mathrm{BC}_{1}$. Such a population is advantageous for QTL mapping because it can be phenotyped with many replicates and in different environments, which makes it possible to detect QTLs with smaller effects and allows also an estimation of the Genotype $\times$ Environment (G x E) interaction (Chaïb et al. 2006; Eshed and Zamir 1996; Gur and Zamir 2004; Lecomte et al. 2004; Monforte et al. 2001). At least five IL populations have been developed in tomato; they are derived from S. pennellii LA716 (Eshed and Zamir 1994), S. habrochaites LA1777 (Monforte and Tanksley 2000), S. habrochaites LA407 (Francis et al. 2001), S. habrochaites LYC4 (Finkers et al. 2007) and S. lycopersicoides LA2951(Canady et al. 2005). The $S$. pennellii IL library has been extensively explored to identify QTLs for several traits including disease resistances (Astua-Monge et al. 2000; Smart et al. 2007), fruit quality (Rousseaux et al. 2005; Tieman et al. 2006) and yield (Eshed et al. 1996). Recently, an introgression line of S. habrochaites LA1777 has been identified with a significant contribution to marketable fruit yield (Hanson et al. 2007).

In this paper we describe the screening of three S. habrochaites accessions (LA1777, LA2099 and LA1033), which have shown high levels of resistance to P. infestans (Brouwer et al. 2004), and we found that of the three accessions LA1777 gave the highest resistance levels to several races of late blight originating from China, especially to $P$. infestans race $\mathrm{T}_{1,2,3,4}$ which already overcame the $P h-1, P h-2$, $P h-3$ and $P h-4$ genes. Since the genetic distance between LA2099 and LA1777 is substantial, LA1777 might harbor other QTLs for late blight resistance as LA2099. In this paper, the IL population derived from S. habrochaites LA1777 (Monforte and Tanksley 2000) has been screened. Results and comparisons with earlier studies are presented and discussed.

\section{Materials and methods}

\section{Plant material}

Three accessions of S. habrochaites (LA1777, LA2099 and LA1033) were tested together with control lines. As susceptible control, we used 
S. lycopersicum 99165 (tomato inbred line derived from the progeny of $\mathrm{OH} 211 \times \mathrm{NS} 217$, USA) and S. lycopersicum HZ14 and HZ18 (two commercial hybrids widely used in China for processing tomato production). As resistance control, we included the inbred line CLN2037B (provided by AVRDC-The World Vegetable Centre) harboring the $P h-3$ gene. Disease testing was always performed after the sixth true leaf had developed.

The introgression lines (IL) used in this study were derived from S. habrochaites accession LA1777 (a self-incompatible, homozygous green fruited, indeterminate accession) in the background of S. lycopersicum E6203 (a red fruited, determinate, processingtype tomato). In total this IL population has 98 ILs that cover at least $85 \%$ of the wild species genome (Monforte and Tanksley 2000). In this study, all these ILs were screened except for LA3973, LA3974, LA3982, LA3987 and LA3992. Since introgressions in different lines overlap and the introgressions in the 93 lines used in this study are located on all the 12 tomato chromosomes, we expect that the 93 lines could still cover about $85 \%$ of the wild species genome. Seeds were kindly provided by the Tomato Genetic Resource Center (TGRC, Davis USA). In order to get new seeds fruits of the individual introgression lines were collected after self pollination in the greenhouse and the accession LA1777 was maintained by pollination with a pollen mixture from different plants.

The seeds were germinated in an incubator at $25^{\circ} \mathrm{C}$ and then transferred to $10 \mathrm{~cm}$ pots containing a medium of peat-vermiculite with organic fertilizer. Greenhouse temperature ranged from 15 to $18^{\circ} \mathrm{C}$ at night and from 20 to $25^{\circ} \mathrm{C}$ at day time.

\section{Inoculum preparation}

Two $P$. infestans isolates from China were used in the resistance assays: $\mathrm{T}_{1,2}$ and $\mathrm{T}_{1,2,4}$ (Chen et al. 2008). Among them, race $T_{1,2}$ is the most epidemic isolate in China and present in eighteen provinces (Dr. Feng IVF, CAAS Beijing, China and Dr. Tian AVRDC, Taiwan; personal communication). Isolates $\mathrm{T}_{1,2}$, and $\mathrm{T}_{1,2,4}$ are virulent on tomato genotypes containing the resistance genes $P h-1$ and $P h-2$ or $P h-1, P h-2$ and $P h-4$, respectively. For the three $S$. habrochaites accessions one extra $P$. infestans race was used. This isolate, $\mathrm{T}_{1,2,3,4}$; is the most virulent race found in
China and was collected in a greenhouse in Beijing, China by the department of Pathology, IVF, CAAS.

Cultures of $P$. infestans were grown at $17^{\circ} \mathrm{C}$ on Rye B agar (Caten and Jinks 1968) and transferred to new plates monthly. Isolates were periodically grown on leaves of susceptible control tomato cv Zaofeng no. 2 to maintain pathogenicity and profuse sporulation. Inoculum for disease assays was prepared by washing 8-day-old sporulating lesions with sterile distilled water. Spore concentrations were determined using a hemocytometer and diluted to the desired concentration $\left(1 \times 10^{4}\right.$ spores $\left.\mathrm{ml}^{-1}\right)$.

\section{Detached-leaflet assay}

The $S$. habrochaites IL population was evaluated by a droplet method using $T_{1,2}$ race in five independent experiments and $\mathrm{T}_{1,2,4}$ race in one independent experiment. Five to fifteen plants of each genotype were used for each experiment. From each individual plant the sixth true leaf was detached with a razor blade and immediately inserted in moist florist foam. The abaxial surface of three of the top leaflets was inoculated with a drop of $20 \mu \mathrm{l}$ of sporangial suspension $\left(1 \times 10^{4}\right.$ spores $\left.\mathrm{ml}^{-1}\right)$. Leaves were transferred to transparent plastic boxes, sealed with a transparent plastic membrane, covered by the lids and randomly placed in a growth cabinet at $16^{\circ} \mathrm{C}$ without light. After $24 \mathrm{~h}$, the regime was changed to $16^{\circ} \mathrm{C}$ with $12 \mathrm{~h}$ light and $12 \mathrm{~h}$ dark. Late blight resistance was assessed six days post inoculation (dpi). The largest length and width (perpendicular to the length) of each lesion was measured resulting in the lesion size (LS) and the ellipse area was calculated following the formula LS $=($ length $\times$ width $\times \pi) / 4$. No lesion or a lesion remaining within the size of the inoculum droplet $\left(\leq 0.3 \mathrm{~cm}^{2}\right)$ was considered as no infection or as arrested lesion (Vleeshouwers et al. 1999). For each genotype, the percentage of successfully infected leaflets was calculated as disease incidence (DI).

Whole plant assay in growth cabinets

Wild species were tested for resistance using a whole plant assay with races $T_{1,2}, T_{1,2,4}$ and $T_{1,2,3,4}$. Greenhouse-grown plants with fully stretched six true leaves were moved to cabinets. Thirty plants of each genotype were evaluated in three blocks using a randomized complete block design. 
For whole plant inoculations, each plant was spray inoculated until the water started to drip off. The dew cabinets had an air temperature of $17-18^{\circ} \mathrm{C}$. The first $24 \mathrm{~h}$ after inoculation no light was used, after this a regime of $12 \mathrm{~h}$ light $\left(18^{\circ} \mathrm{C}\right): 12 \mathrm{~h}$ dark $\left(16^{\circ} \mathrm{C}\right)$ was used. After seven days the plants were scored individually for disease severity on a scale of $0-6$, where $0=$ no symptoms; $1=<5 \%$ leaf area affected and small $(<2 \mathrm{~mm})$ lesions; $2=6-15 \%$ leaf area affected and restricted $(<4 \mathrm{~mm})$ lesions; $3=16-30 \%$ leaf area affected and/or few superficial small stem lesions; $4=31-60 \%$ leaf area affected and/or few small penetrating stem lesions; $5=61-90 \%$ leaf area affected and/or deep expanding stem lesions; $6=$ 91-100\% leaf area affected, extensive stem damage, or plant death (Chunwongse et al. 2002; Brouwer et al. 2004). Percentage disease index (PDI) was calculated with the following formula for each genotype: PDI $=$ sum of all ratings $\times 100 /$ total no. of observations $\times$ maximum rating grade (Chaerani et al. 2007).

\section{Statistical analysis}

All statistical analyses were performed using SPSS 13.0. Differences in $P$. infestans resistance in the $S$. habrochaites IL population were analyzed using the procedure of general linear model (GLM). LS data was transformed by square root to meet a normal distribution. Mean estimates for each IL line were calculated using the following models: PDI $=$ constant + genotype + block + genotype $\times$ block. $\mathrm{LS}=$ constant + genotype + experiment + genotype $\times$ experiment. DI $=$ constant + genotype + experiment + genotype $\times$ experiment. The correlation between traits was calculated by Pearson correlation coefficients. Trait data for experiments were tested for homogeneity of variance using a Levene test in order to evaluate the normal distribution. Significance of QTL was determined by comparing mean values of individual ILs to the control S. lycopersicum E6203 at the 0.05 level by Dunnett test.

\section{Results}

Comparison of three accessions

of $S$. habrochaites with whole plant assay

From an earlier experiment it was clear that S. habrochaites accession LA1777 was resistant to
$P$. infestans race $\mathrm{T}_{1,2}$ (Fig. 1). Analysis of different accessions and controls with race $\mathrm{T}_{1,2,4}$ of $P$. infestans (Fig. 2) show that all three accessions of the wild species $S$. habrochaites gave a good resistance level to that particular race. However, the two accessions LA1777 and LA2099 with a mean PDI of 20.0 and 21.7 were more resistant than the accession LA1033 (mean PDI 34), but all were significantly more resistant than the susceptible controls (mean PDI 86.1). The same two accessions of $S$. habrochaites (LA1777 and LA2099) also showed enhanced resistance levels to the most virulent race: $\mathrm{T}_{1,2,3,4}$ (Fig. 2).

Detached leaflet assay in LA1777 IL population with race $T_{1,2}$

The IL population was analyzed with the detached leaflet assay using isolate $T_{1,2}$ in five independent experiments over two years. Two traits were evaluated for each individual ILs: lesion size (LS) expressed as the mean size of $P$. infestans lesions of infected leaves, and disease incidence (DI) expressed as the percentage of inoculated leaves that were successfully infected.

Between experiments, the mean LS varied from $2.34 \pm 0.06$ to $5.00 \pm 0.05 \mathrm{~cm}^{2}$, while the mean DI varied from $75.6 \pm 0.9$ to $84.0 \pm 0.6 \%$ for the IL population. The disease scorings of LS were higher in 2006 than in 2007. However, the mean DI remained more or less the same over all five experiments. Significant correlations were observed for LS between experiments 1,2 , 4 and 5 ( $r=0.21-0.37, P<0.05$ or $P<0.01)$ but no significant correlation was present with the LS of experiment 3 (Table 2). Experiment 3 was excluded for the final analysis of the results, but this only influenced the level of significance for each IL. Significant correlations for DI were only observed between experiments 1 and $4(r=0.357, P<0.01)$, and between experiments 3 and $5(r=0.283, P<$ $0.05)$. The data of the experiments with significant correlation were analyzed. There is a significant difference between $S$. habrochaites LA1777 (2.33 \pm $\left.0.31 \mathrm{~cm}^{2}\right)$ and $S$. lycopersicum E6203 (4.05 \pm $0.16 \mathrm{~cm}^{2}$ ) and the mean LS ranged from $2.89 \pm$ 0.19 to $6.28 \pm 0.48 \mathrm{~cm}^{2}$ among the ILs. A total of fifty-four lines showed smaller LS (0.30-28.5\%) and this was significant in thirty-one lines. Thirty-two lines identified herein can harbor a number of QTLs conferring resistance to $P$. infestans as determined by LS (Table 1). We designated the identified QTLs as 
Fig. 1 Screening of tomato wild species for resistance to $P$. infestans race $\mathrm{T}_{1,2}$. Top left $S$. habrochaites LA1777. Top right the susceptible control S. lycopersicum 99165. Bottom left the susceptible control S. lycopersicum HZ14. Bottom right the resistant control S. lycopersicum CLN2037B with $P h-3$ gene (provided by AVRDC)

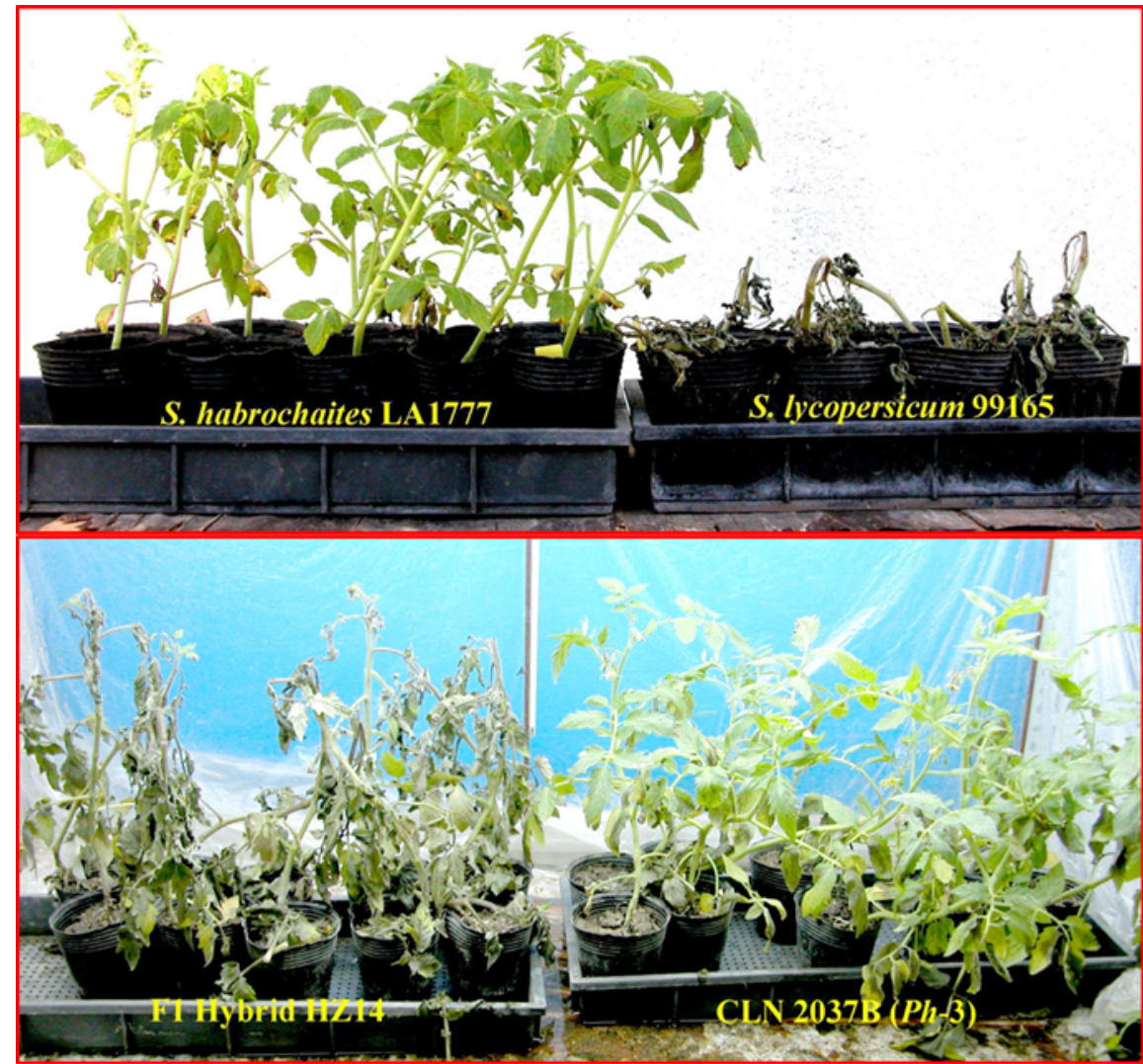

most significant and substantial QTLs, which were located on chromosomes 4 (2 QTLs), 7, 8 and 12.

$R l b q 4 \mathrm{a}$ and Rlbq4b. Sixteen of the 93 lines contain an introgression of chromosome 4 . Ten of these lines were significantly more resistant than the control (Table 2 and Fig. 3). The significant effects in lines LA3931, LA3959, LA3979 and LA4006 show the presence of a QTL (Rlbq4a) at the top of Chromosome 4. More markers will have to be determined to pinpoint the QTL more precisely. The fact that lines LA3930 and LA4000 are not resistant will make it likely that the position can be determined rather precisely. However, also some lines with other introgressions on Chromosome 4 had higher resistance levels, the significant higher resistance levels of ILs LA3934, LA3935, LA3937, LA3976 and LA4007 shows that there must be a second QTL (Rlbq4b) towards the bottom of Chromosome 4. Again additional markers are needed to explain why lines such as LA3936, LA3977 and LA3978 do not show resistance.

In the same manner, we identified three other QTLs for smaller LS: on top of Chromosome 7: Rlbq7, and LA1777 were distributed on 11 of the 12 chromosomes. We will focus in this paper only on the five 
Table 1 Estimated mean of lesion size (LS) and disease incidence (DI) in introgression lines (IL) and their two parents, resistant S. habrochaites LA1777 and susceptible S. lycopersicum cv. E6203

\begin{tabular}{|c|c|c|c|c|}
\hline ILs & $\operatorname{LS}\left(\mathrm{cm}^{2}\right)$ & $\mathrm{N}^{\mathrm{a}}$ & DI $(\%)$ & $\mathrm{N}^{\mathrm{b}}$ \\
\hline LA3915 & $3.91 \pm 0.21 *$ & 98 & $83.8 \pm 4.6$ & 117 \\
\hline LA3916 & $3.76 \pm 0.19 *$ & 107 & $86.3 \pm 3.9$ & 124 \\
\hline LA3918 & $3.95 \pm 0.21 *$ & 97 & $82.9 \pm 4.2$ & 117 \\
\hline LA3919 & $3.72 \pm 0.24 * *$ & 86 & $72.9 \pm 4.5$ & 118 \\
\hline LA3921 & $3.75 \pm 0.20 * *$ & 101 & $82.1 \pm 4.2$ & 123 \\
\hline LA3922 & $3.92 \pm 0.20^{* *}$ & 97 & $85.1 \pm 4.3$ & 114 \\
\hline LA3923 & $3.66 \pm 0.22 * *$ & 83 & $76.6 \pm 4.4$ & 109 \\
\hline LA3925 & $3.52 \pm 0.21 * *$ & 88 & $82.2 \pm 4.3$ & 107 \\
\hline LA3929 & $3.48 \pm 0.19 * *$ & 101 & $82.8 \pm 4.0$ & 122 \\
\hline LA3931 & $3.82 \pm 0.19 *$ & 106 & $82.2 \pm 3.9$ & 129 \\
\hline LA3932 & $3.61 \pm 0.22 * *$ & 82 & $73.9 \pm 4.0$ & 111 \\
\hline LA3934 & $3.49 \pm 0.21 * *$ & 95 & $76.6 \pm 4.3$ & 124 \\
\hline LA3935 & $3.59 \pm 0.22 * *$ & 93 & $76.9 \pm 4.6$ & 121 \\
\hline LA3937 & $3.20 \pm 0.21 * *$ & 85 & $72.0 \pm 3.9$ & 118 \\
\hline LA3941 & $3.19 \pm 0.26^{* *}$ & 64 & $66.0 \pm 4.8^{*}$ & 97 \\
\hline LA3948 & $3.67 \pm 0.21 *$ & 92 & $74.8 \pm 3.9$ & 123 \\
\hline LA3949 & $2.89 \pm 0.19 * *$ & 102 & $77.3 \pm 3.7$ & 132 \\
\hline LA3959 & $3.39 \pm 0.19 * *$ & 102 & $82.3 \pm 3.8$ & 124 \\
\hline LA3961 & $3.72 \pm 0.21 *$ & 96 & $76.2 \pm 3.9$ & 126 \\
\hline LA3963 & $3.67 \pm 0.19 *$ & 100 & $84.0 \pm 3.8$ & 119 \\
\hline LA3964 & $3.92 \pm 0.21 *$ & 84 & $83.2 \pm 4.4$ & 101 \\
\hline LA3965 & $3.56 \pm 0.18^{* *}$ & 107 & $80.9 \pm 3.6$ & 132 \\
\hline LA3967 & $3.40 \pm 0.20 *$ & 101 & $82.8 \pm 3.9$ & 122 \\
\hline LA3969 & $3.46 \pm 0.19 * *$ & 111 & $88.8 \pm 4.0$ & 125 \\
\hline LA3976 & $3.45 \pm 0.19 * *$ & 108 & $87.1 \pm 3.9$ & 124 \\
\hline LA3979 & $3.75 \pm 0.22 * *$ & 86 & $76.1 \pm 4.3$ & 113 \\
\hline LA3988 & $3.73 \pm 0.22 * *$ & 88 & $80.7 \pm 4.7$ & 109 \\
\hline LA3989 & $3.75 \pm 0.19 * *$ & 113 & $88.3 \pm 3.9$ & 128 \\
\hline LA3990 & $3.95 \pm 0.20 *$ & 85 & $70.8 \pm 3.8$ & 120 \\
\hline LA4006 & $3.59 \pm 0.17 * *$ & 119 & $86.2 \pm 3.6$ & 138 \\
\hline LA4007 & $3.74 \pm 0.19 *$ & 104 & $83.9 \pm 3.9$ & 124 \\
\hline LA3954 & $3.78 \pm 0.21$ & 84 & $65.6 \pm 3.7^{*}$ & 128 \\
\hline E6203 & $4.05 \pm 0.16$ & 141 & $83.4 \pm 3.3$ & 169 \\
\hline LA1777 & $2.33 \pm 0.31 * *$ & 51 & $38.9 \pm 5.7 * *$ & 131 \\
\hline
\end{tabular}

Means of each trait for each IL were compared to the mean of the susceptible parent using a Dunnett test by GLM mode and significant differences are marked with $*(P<0.05)$ or ** $(P<0.01)$

a Number of leaflets that had lesion growth

b Number of leaflets that were tested in four experiments
Fig. 3 Rows indicate introgression line (IL) and columns indicate chromosomes. For each chromosome, the top and bottom is from the left to right. Solid segments show introgressions in the IL based on Monforte and Tanksley (2000). Following each IL, the asterisk showed the significant differences as compared to the susceptible control $S$. lycopersicum E6203 for leaf LS ( $* P<0.05$ and $* * P<0.01$ ). The arrows indicate the most likely location of the identified QTLs through their overlapped ILs

bottom of Chromosome 8: Rlbq8, and the middle of Chromosome 12: Rlbq12 (Table 2 and Fig. 3).

The mean DI of $S$. habrochaites LA1777 was $55.9 \%$, a significant lower value than in the susceptible parent S. lycopersicum E6203 with 83.4\%. The values of the individual lines of the IL population varied from 65.6 to $90.8 \%$. Two lines, LA3941 (Chr. 5) and LA3954 (Chr. 8), showed a significantly decreased DI. However, this was not confirmed in other lines with overlapping introgressions. Hence, the identified QTLs must be further confirmed in additional experiments.

Detached leaflet assay in LA1777 IL population with race $T_{1,2,4}$

In order to see whether the identified resistance is real and consistent, the more virulent race $T_{1,2,4}$ was used in one experiment. The difference in LS between the parental lines S. habrochaites LA1777 $\left(0.91 \pm 0.26 \mathrm{~cm}^{2}\right)$ and S. lycopersicum E6203 $\left(3.20 \pm 0.29 \mathrm{~cm}^{2}\right)$ was highly significant. For the individuals of the IL population LS varied from $1.22 \pm 0.26 \mathrm{~cm}^{2}$ (line LA3918) to $6.39 \pm 0.25 \mathrm{~cm}^{2}$ (LA3969). Of the 93 IL lines, $53 \mathrm{had}$ a reduced LS ranging from 0.67 to $61.85 \%$. Twelve lines gave a significant difference; these were LA3914, LA3918, LA3920, LA3922, LA3923, LA3928, LA3937, LA3948, LA3981, LA3999, LA4004 and LA4005. Five lines, LA3918, LA3922, LA3923, LA3937 and LA3948 were also identified after inoculation with race $\mathrm{T}_{1,2}$. All lines containing QTL Rlbq4b or Rlbcq7 showed lower LS than the control.

The mean DI of S. habrochaites LA1777 (63.4\%) was significantly different from the DI of S. lycopersicum E6203 (83.4\%). The DI ranged among the individuals of the IL population from 66.0 to $92.7 \%$ (data not shown), but were not significantly different from the control. 


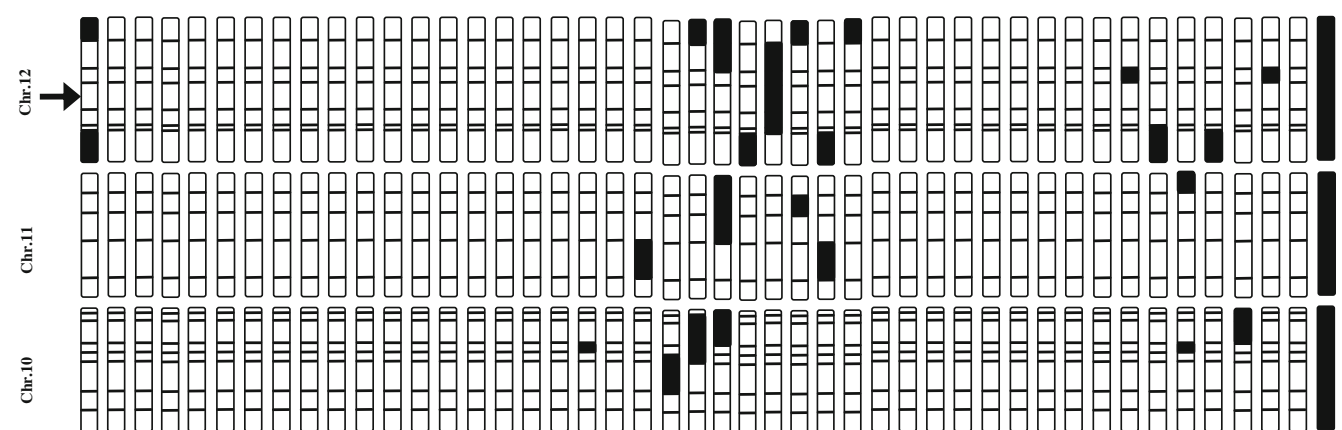

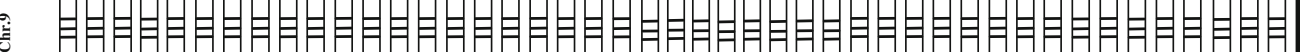

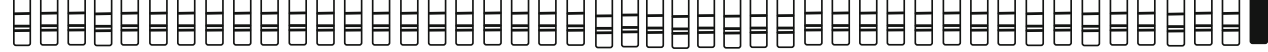
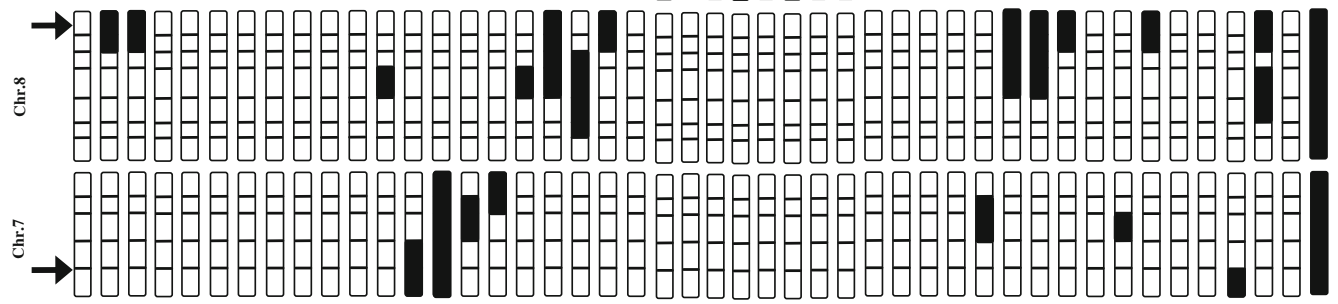

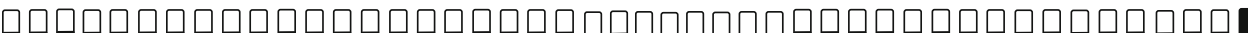
-

8

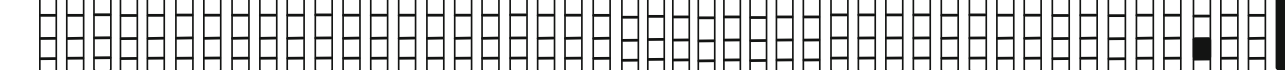

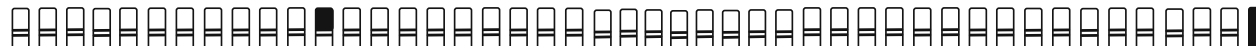

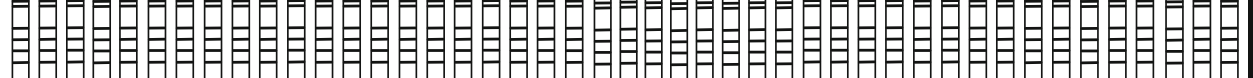

䒠

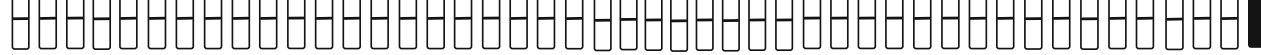

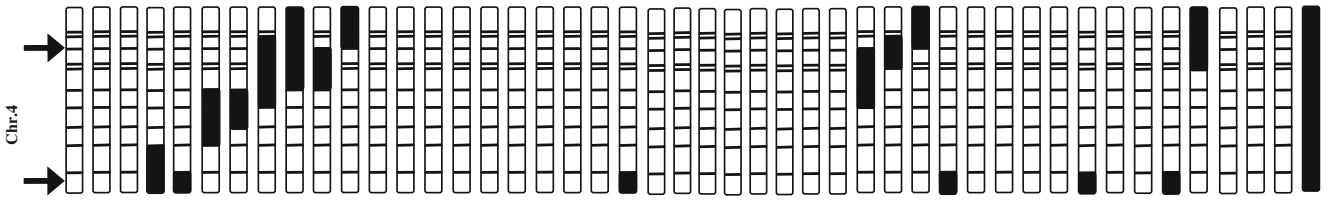

(1)

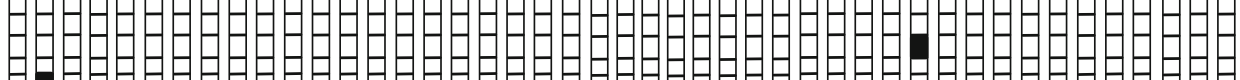

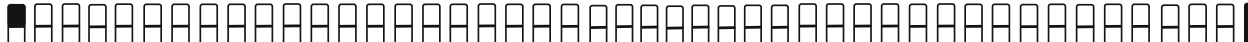

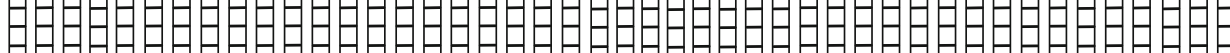

¿

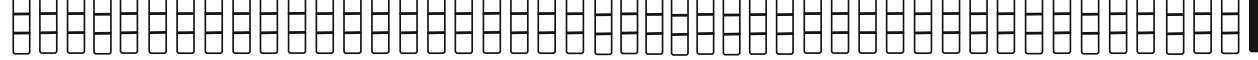

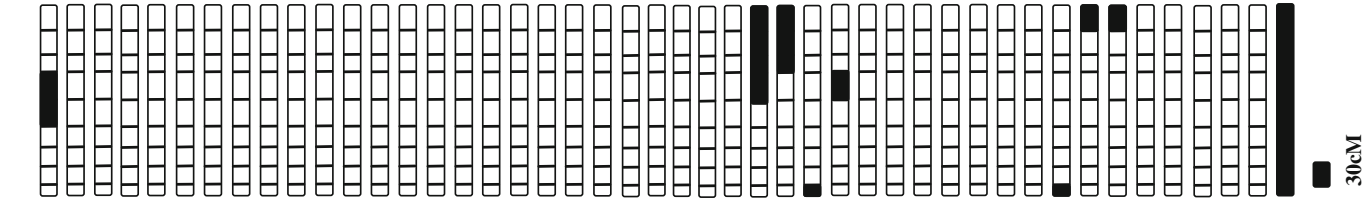

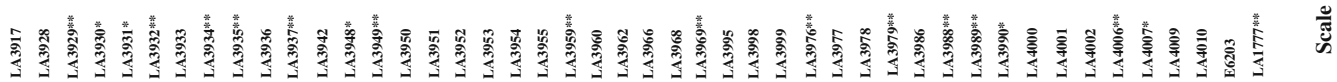




\section{Discussion}

Wild species conferring resistance to $P$. infestans

Three wild species, S. pimpinellifolium, S. pennellii and $S$. habrochaites, have been reported to give qualitative and quantitative resistance to $P$. infestans (Chunwongse et al. 2002; Conver and Walter 1953; Moreau et al. 1998; Smart et al. 2007; Turkensteen 1973). Quantitative resistance in plants has been shown to be more durable (Brun et al. 2010; Palloix et al. 2009). In $S$. habrochaites a high level of

Table 2 Leaf lesion size (LS) assayed in four independent experiments, and means of LS and disease incidence (DI) of ILs containing the introgressions and their overlapped ILs on chromosome 4, 7, 8 and 12, respectively and two parent lines

\begin{tabular}{|c|c|c|c|c|c|c|c|}
\hline \multirow[t]{2}{*}{ IL } & \multirow[t]{2}{*}{ QTL } & \multicolumn{4}{|c|}{ LS $\left(\mathrm{cm}^{2}\right)$ in four experiments } & \multirow[t]{2}{*}{ Mean LS $\left(\mathrm{cm}^{2}\right)$} & \multirow{2}{*}{$\begin{array}{l}\text { Mean DI } \\
(\%)\end{array}$} \\
\hline & & 1 & 2 & 4 & 5 & & \\
\hline LA3930 & $R l b q 4 \mathrm{a}$ & 4.62 & 5.84 & 2.28 & 3.49 & $4.06 \pm 0.20$ & $76.8 \pm 3.8$ \\
\hline LA3931 & & 4.81 & 5.11 & 2.28 & 3.09 & $3.82 \pm 0.19 *$ & $83.4 \pm 3.9$ \\
\hline LA3932 & & 4.56 & 4.40 & 2.43 & 3.04 & $3.61 \pm 0.23 * *$ & $72.0 \pm 4.0$ \\
\hline LA3933 & & 5.19 & 5.50 & 3.06 & 4.27 & $4.50 \pm 0.18$ & $86.7 \pm 3.9$ \\
\hline LA3959 & & 4.66 & 3.84 & 2.41 & 2.64 & $3.39 \pm 0.19 * *$ & $81.1 \pm 3.8$ \\
\hline LA4000 & & 5.85 & 5.29 & 2.70 & 3.34 & $4.30 \pm 0.20$ & $76.5 \pm 4.0$ \\
\hline LA4006 & & 4.38 & 4.19 & 2.58 & 3.20 & $3.59 \pm 0.17 * *$ & $85.3 \pm 3.6$ \\
\hline LA3934 & $R l b q 4 \mathrm{~b}$ & 4.62 & 4.75 & 2.18 & 2.39 & $3.49 \pm 0.21 * *$ & $78.9 \pm 4.3$ \\
\hline LA3935 & & 5.51 & 3.73 & 2.58 & 2.54 & $3.59 \pm 0.22 * *$ & $81.0 \pm 4.6$ \\
\hline LA3936 & & 4.53 & 4.33 & 2.84 & 3.38 & $3.78 \pm 0.19$ & $83.7 \pm 3.9$ \\
\hline LA3937 & & 3.83 & 3.29 & 2.34 & 3.34 & $3.20 \pm 0.21 * *$ & $70.5 \pm 3.9$ \\
\hline LA3976 & & 4.33 & 3.96 & 2.77 & 2.73 & $3.45 \pm 0.19 * *$ & $86.1 \pm 3.9$ \\
\hline LA3977 & & 6.38 & 4.80 & 2.76 & 3.16 & $4.27 \pm 0.24$ & $71.9 \pm 4.7$ \\
\hline LA3978 & & 4.77 & 3.65 & 3.18 & 3.84 & $3.86 \pm 0.21$ & $71.0 \pm 4.1$ \\
\hline LA3979 & & 3.71 & 5.13 & 2.70 & 3.46 & $3.75 \pm 0.22 * *$ & $73.8 \pm 4.3$ \\
\hline LA4007 & & 4.96 & 3.79 & 2.58 & 3.57 & $3.73 \pm 0.19 *$ & $82.9 \pm 3.9$ \\
\hline LA3948 & $R l b q 7$ & 4.36 & 4.24 & 2.74 & 3.35 & $3.67 \pm 0.21 *$ & $73.1 \pm 3.9$ \\
\hline LA3949 & & 3.66 & 3.39 & 1.90 & 2.62 & $2.89 \pm 0.19 * *$ & $77.4 \pm 3.7$ \\
\hline LA3950 & & 5.24 & 6.34 & - & 7.28 & $6.28 \pm 0.48$ & $65.8 \pm 8.9$ \\
\hline LA3951 & & 5.93 & 5.06 & 2.60 & 3.98 & $4.39 \pm 0.18$ & $82.1 \pm 3.7$ \\
\hline LA3985 & & 4.42 & 5.85 & 3.39 & 4.96 & $4.66 \pm 0.21$ & $87.3 \pm 4.6$ \\
\hline LA3986 & & 4.16 & 2.19 & 2.99 & 4.41 & $3.44 \pm 0.21$ & $78.0 \pm 4.3$ \\
\hline LA4001 & & 5.46 & 4.21 & 3.18 & 3.45 & $4.08 \pm 0.22$ & $85.5 \pm 4.6$ \\
\hline LA4009 & & 5.72 & 4.65 & - & - & $5.19 \pm 0.42$ & $69.0 \pm 7.9$ \\
\hline LA3928 & Rlbq 8 & 3.66 & 5.31 & - & - & $4.49 \pm 0.34$ & $76.2 \pm 6.4$ \\
\hline LA3929 & & 4.43 & 4.61 & 2.06 & 2.80 & $3.48 \pm 0.19 * *$ & $82.3 \pm 4.0$ \\
\hline LA3942 & & 4.39 & 3.81 & 3.22 & 3.61 & $3.76 \pm 0.20$ & $70.6 \pm 3.8$ \\
\hline LA3952 & & 5.24 & 4.26 & 2.59 & 3.595 & $3.92 \pm 0.18$ & $78.8 \pm 3.7$ \\
\hline LA3953 & & 4.65 & 4.57 & 2.79 & 3.10 & $3.78 \pm 0.20$ & $84.1 \pm 4.0$ \\
\hline LA3954 & & 4.97 & 4.15 & 2.85 & 3.16 & $3.78 \pm 0.20$ & $65.6 \pm 3.7 * *$ \\
\hline LA3955 & & 4.19 & 5.09 & 3.54 & 2.71 & $3.88 \pm 0.19$ & $80.6 \pm 3.8$ \\
\hline LA3988 & & 5.52 & 3.55 & 3.19 & 2.66 & $3.73 \pm 0.22 * *$ & $85.2 \pm 4.7$ \\
\hline LA3989 & & 5.36 & 4.06 & 2.31 & 3.28 & $3.75 \pm 0.19 * *$ & $86.0 \pm 3.9$ \\
\hline LA3990 & & 5.14 & 5.09 & 2.32 & 3.27 & $3.95 \pm 0.20 *$ & $69.9 \pm 3.8 * *$ \\
\hline LA4002 & & 5.09 & 4.38 & 3.64 & 4.05 & $4.29 \pm 0.22$ & $78.2 \pm 4.4$ \\
\hline LA4010 & & 6.57 & 4.67 & 2.82 & 3.88 & $4.48 \pm 0.19$ & $84.2 \pm 3.9$ \\
\hline
\end{tabular}


Table 2 continued

\begin{tabular}{|c|c|c|c|c|c|c|c|}
\hline \multirow[t]{2}{*}{ IL } & \multirow[t]{2}{*}{ QTL } & \multicolumn{4}{|c|}{ LS $\left(\mathrm{cm}^{2}\right)$ in four experiments } & \multirow[t]{2}{*}{ Mean LS $\left(\mathrm{cm}^{2}\right)$} & \multirow{2}{*}{$\begin{array}{l}\text { Mean DI } \\
(\%)\end{array}$} \\
\hline & & 1 & 2 & 4 & 5 & & \\
\hline LA3917 & \multirow[t]{15}{*}{$R l b q 12$} & 5.55 & 5.53 & 2.92 & 3.38 & $4.35 \pm 0.28$ & $67.6 \pm 5.5^{*}$ \\
\hline LA3960 & & 4.79 & 4.52 & 2.45 & 3.47 & $3.81 \pm 0.19$ & $81.3 \pm 3.5$ \\
\hline LA3962 & & 5.40 & 5.56 & 2.74 & 3.48 & $4.29 \pm 0.18$ & $81.0 \pm 3.5$ \\
\hline LA3966 & & 6.23 & 4.90 & 3.18 & 3.57 & $4.47 \pm 0.22$ & $88.8 \pm 3.8$ \\
\hline LA3968 & & 5.45 & 5.75 & 3.28 & 3.24 & $4.43 \pm 0.19$ & $72.5 \pm 3.5$ \\
\hline LA3969 & & 4.28 & 4.09 & 2.36 & 3.12 & $3.46 \pm 0.19 * *$ & $88.4 \pm 3.7$ \\
\hline LA3995 & & 4.61 & 5.19 & 3.03 & 3.56 & $4.10 \pm 0.20$ & $86.9 \pm 3.6$ \\
\hline LA3998 & & 5.11 & 6.16 & 3.76 & 4.02 & $4.76 \pm 0.20$ & $81.8 \pm 3.8$ \\
\hline LA3999 & & 3.97 & 6.24 & 3.64 & 2.55 & $4.10 \pm 0.18$ & $79.2 \pm 3.3$ \\
\hline LA4001 & & 5.46 & 4.21 & 3.18 & 3.45 & $4.08 \pm 0.22$ & $83.1 \pm 4.1$ \\
\hline LA4002 & & 5.09 & 4.38 & 3.64 & 4.05 & $4.29 \pm 0.22$ & $78.6 \pm 4.0$ \\
\hline LA4007 & & 4.96 & 3.79 & 2.58 & 3.77 & $3.73 \pm 0.29 *$ & $83.6 \pm 3.6$ \\
\hline LA4010 & & 6.57 & 4.67 & 2.82 & 3.88 & $4.48 \pm 0.29$ & $84.7 \pm 3.6$ \\
\hline E6203 & & 6.23 & 4.05 & 3.10 & 2.94 & $4.05 \pm 0.16$ & $83.4 \pm 3.3$ \\
\hline LA1777 & & 2.75 & 2.17 & 2.25 & 2.51 & $2.33 \pm 0.31 * *$ & $55.9 \pm 5.7$ \\
\hline
\end{tabular}

Means of LS for each IL were compared to the mean of the susceptible parent using a Dunnett test by GLM mode and significant differences are marked with $*(P<0.05)$ or $* *(P<0.01)$

quantitative resistance to several isolates has been found (Brouwer et al. 2004). In our study, three wild accessions of $S$. habrochaites were evaluated for resistance to different races of $P$. infestans and the resistance level of the three accessions is quite different for two races of $P$. infestans. Accessions LA1777 and LA2099 had a higher level of resistance to race $T_{1,2,4}$ than accession LA1033. To the most virulent race $T_{1,2,3,4}$ accession LA1033 was almost completely susceptible in contrast to a very good level of resistance in both LA1777 and LA2099. The virulence of race $T_{1,2,3,4}$ on accession LA1033 maybe caused by the fact that this accession has allelic variants of the $P h-3$ gene, a gene which can be overcome by race $\mathrm{T}_{1,2,3}$ (Chunwongse et al. 2002). Brouwer et al. (2004) have shown that LA2099 has a very good resistance to USA isolates 7629 and 9175 , which are virulent on tomato genotypes containing the $P h-1$ and $P h-2$ gene. We found in this study that LA1777 and LA2099 have potential resistances to several other races of $P$. infestans with LA1777 as the most resistant. Recently, two new resistance genes, $P h-4$ and $P h-5$, have been identified from S. pimpinellifolium (Foolad et al. 2008; Kole et al. 2006) and another gene located on chromosome 6 of S. pennellii was described by Smart et al. (2007). We also screened a nightshade $S$. lycopersicoides LA2951 IL population and it seems that this population also harbors resistance to $P$. infestans (data not shown). Hence, it might be that more wild species can serve as potential sources for resistance genes to $P$. infestans. These wild species provide a rich resource for breeding tomatoes with resistance to late blight.

QTLs identified in different experiments

We have made an effort to explore introgression lines of S. habrochaites LA1777 for resistance loci against $P$. infestans by a detached leaflet assay. As a permanent population, these ILs allowed us to test them with a major race $\left(\mathrm{T}_{1,2}\right)$ of $P$. infestans in five independent detached leaf experiments over two years. The mean LS in these two years varied greatly which might be caused by inoculum quality or differences in individual lines under different experimental conditions (Vleeshouwers et al. 1999) and each genotype from an IL population might adapt in a different way to the environment. Low to moderately low correlations were also reported among different assay methods (Brouwer et al. 2004). To identify introgressions with 
resistance genes only the experiments with significant correlation between experiments were used in this study. While analyzing the data of IL populations, the five QTLs could only be identified after combining the data of four independent experiments because not all of them were significant in single experiments. Some of the identified QTLs were not detected when another inoculum (race $\mathrm{T}_{1,2,4}$ ) was used. In conclusion independent experiments are needed in search for quantitative resistance to $P$. infestans. The whole-plant assay was also used to screen the $S$. habrochaites LA1777 IL population in three replications (data not shown). However, only small differences could be observed between ILs and the susceptible control. With the detached leaf assay substantial differences were observed. Brouwer et al. (2004) reported that neither a detached leaflet nor a whole-plant assay can entirely substitute $P$. infestans screenings in tomato. Hence, field or greenhouse tests should add more evidence to prove the true nature of the identified QTLs (Brouwer et al. 2004).

DI as a measure for infection efficiency was also evaluated in our study. For DI, low or no correlation between experiments was found and QTLs responsible for DI could not be identified in this study. Vleeshouwers et al. (1999) showed that a highly constant humidity in closed trays apparently enhances infection by the zoospores causing a very high disease pressure. In our experiments, the plastic box is always covered by the lid, which would enhance the chance for the successful infection as proved by Vleeshouwers et al. (1999) and Brouwer et al. (2004). In the detached leaf assay some well known resistant wild Solanum genotypes were partially infected. A high amount of successful infections reduces the change to find QTLs for disease incidence but makes the chance higher to find QTLs for LS (more data points). Vleeshouwers et al. (1999) suggested when the DI is to be used as a parameter for resistance, a different screening methodology must be chosen, e.g., incubation of detached leaves in open trays, or intact plants in climate chamber or field. Other complicating factors in a bioassay can be the significant negative correlation between percentage infection and plant height (Brouwer et al. 2004) and rotting of leaves during the evaluation. Brouwer et al. (2004) found that determinate genotypes were more susceptible at least to late blight than indeterminate genotypes because the indeterminate type is higher than the determinate type. In our paper, all of ILs are determinate type, which would be more susceptible. Also, we tried not to include these rotten leaves in the data analysis, but it is sometimes difficult to distinguish between infected and rotten leaves. This can be the reason that introgression lines appear to be more susceptible than the control as the leaves of $S$. habrochaites LA1777 rot more easily than the leaves of the ILs.

In this study we only focused on lines with larger effect on resistance to $P$. infestans. Only QTLs identified in several lines with overlapping introgressions are considered as reliable. Since the IL population we used covered about $85 \%$ of the genome of LA1777 accession, some QTLs for resistance to $P$. infestans might be missed therefore. Moreover, the exact location of each QTL still needs to be confirmed due to lack of precise flanking markers in each introgression line.

Comparative analysis of QTLs from different populations

On all 12 tomato chromosomes many QTLs for resistance to $P$. infestans have been detected in another S. habrochaites accession namely LA2099 with only eight QTLs showed consistent resistance over experiments (Brouwer et al. 2004). We found that Rlbq4a, Rlbq7, Rlbq8b and Rlbhq12 co-localize with previously identified $l b 4 a, l b 7 a, l b 8 b$ and $l b 12 b$ respectively on chromosome 4, 7, 8 and 12 (Brouwer et al. 2004). Because Rlbq4b was not detected in the previous study and the fact that it showed a good resistance against two different races of late blight, we think that this novel QTL from LA1777 is important and worthwhile introgressing in tomato varieties. A next step could be to clone the genes underlying these QTLs.

\section{Potential of pyramiding QTLs}

Up to now, both qualitative and quantitative genes have been identified in several different wild tomato species. The interaction between these QTLs and single genes is still unknown but lines with all four QTLs, from S. habrochaites LA2099, have shown a high level of resistance to $P$. infestans under different environments (Brouwer et al. 2004; Brouwer and St Clair 2004). In our study, five QTLs have been 
identified and two of them give also resistance to the most virulent race. Not all QTLs were identified in each experiment and in all lines with overlapping introgressions, indicating that most QTLs have a limited effect and interactions between QTLs as well as between QTLs and environment play a role in obtaining a high level of resistance. Combining QTLs and single resistance genes can be beneficial for durability of the resistance to several fungi (Brun et al. 2010; Palloix et al. 2009; Stall et al. 2009). Therefore we suggest to develop combinations of several QTLs or QTLs and single genes, not only from one wild species but also from different wild species. For example a combination of QTL Rlbq4b derived from S. habrochaites LA1777, one QTL derived from S. pennellii LA716 (Smart et al. 2007) and some QTLs derived from $S$. habrochaites LA2099 (Brouwer et al. 2004). In this way pyramiding of these or similar effective QTLs might pave the way for durable resistance to P. infestans.

Acknowledgments This project was sponsored by National Basic Research and Development Program (2009CB119000), Hi-Tech Research and Development Program (2006AA10 Z1A6), Key Laboratory of Horticultural Crops Genetic Improvement (Ministry of Agriculture of the People's Republic of China), the Royal Dutch Academy of Sciences (KNAW) and the Asian Facility (project AF01/CH/8 "SinoDutch Genomic Lab and Vegetable Research Center). The authors would like to thank Dr. Guusje Bonnema for the experimental suggestions. Zhang Pujuan, Wang Baike, Wu Yuhui, Su Caixia and Fan Weiqiang are acknowledged for their kind help during the artificial inoculation.

Open Access This article is distributed under the terms of the Creative Commons Attribution Noncommercial License which permits any noncommercial use, distribution, and reproduction in any medium, provided the original author(s) and source are credited.

\section{References}

Astua-Monge G, Minsavage GV, Stall RE, Vallejos CE, Davis MJ, Jones JB (2000) Xv4-vrxv4: a new gene-for-gene interaction identified between Xanthomonas campestris pv. Vesicatoria race $\mathrm{T} 3$ and the wild tomato relative Lycopersicon pennellii. Mol Plant Microbe Interact 13:1346-1355

Brouwer DJ, St Clair DA (2004) Fine mapping of three quantitative trait loci for late blight resistance in tomato using near isogenic lines (NILs) and sub-NILs. Theor Appl Genet 108:628-638
Brouwer DJ, Jones ES, St Clair DA (2004) QTL analysis of quantitative resistance to Phytophthora infestans (late blight) in tomato and comparisons with potato. Genome 47:475-492

Brun H, Chevre AM, Fitt BDL, Powers S, Besnard AL, Ermel M, Huteau V, Marquer B, Eber F, Renard M, Andrivon D (2010) Quantitative resistance increases the durability of qualitative resistance to Leptosphaeria maculans in Brassica napus. New Phytol 185:285-299

Canady MA, Meglic V, Chetelat RT (2005) A library of Solanum lycopersicoides introgression lines in cultivated tomato. Genome 48:685-697

Caten C, Jinks J (1968) Variation spontaneous variability of single isolates of Phytophthora infestans I. cultural. Can J Bot $46: 329$

Chaerani R, Smulders MJ, van der Linden CG, Vosman B, Stam P, Voorrips RE (2007) QTL identification for early blight resistance (Alternaria solani) in a Solanum lycopersicum x S. arcanum cross. Theor Appl Genet 114: $439-450$

Chaïb J, Lecomte L, Buret M, Causse M (2006) Stability over genetic backgrounds, generations and years of quantitative trait locus (QTLs) for organoleptic quality in tomato. Theor Appl Genet 112:934-944

Chen CH, Sheu ZM, Wang TC (2008) Host specificity and tomato-related race composition of Phytophthora infestans isolates in Taiwan during 2004 and 2005. Plant Dis 92:751-755

Chunwongse J, Chunwongse C, Black L, Hanson P (2002) Molecular mapping of the $P h-3$ gene for late blight resistance in tomato. J Hortic Sci Biotech 77:281-286

Drenth A, Janssen EM, Govers F (1995) Formation and survival of oospores of Phytophthora infestans under natural conditions. Plant Pathol 44:86-94

Eshed Y, Zamir D (1994) A Genomic library of Lycopersicon pennellii in Lycopersicon esculentum - a tool for fine mapping of genes. Euphytica 79:175-179

Eshed Y, Zamir D (1996) Less-than-additive epistatic interactions of quantitative trait loci in tomato. Genetics 143: 1807-1817

Eshed Y, Gera G, Zamir D (1996) A genome-wide search for wild-species alleles that increase horticultural yield of processing tomatoes. Theor Appl Genet 93:877-886

Finkers R, van Heusden A, Meijer-Dekens F, van Kan J, Maris P, Lindhout P (2007) The construction of a Solanum habrochaites LYC4 introgression line population and the identification of QTLs for resistance to Botrytis cinerea. Theor Appl Genet 114:1071-1080

Foolad MR, Merk HL, Ashrafi H (2008) Genetics, genomics and breeding of late blight and early blight resistance in tomato. Crit Rev Plant Sci 27:75-107

Francis DM, Kabelka E, Bell J, Franchino B, St. Clair D (2001) Resistance to bacterial canker in tomato (Lycopersicon hirsutum LA407) and its progeny derived from crosses to L. esculentum. Plant Dis 85:1171-1176

Goodwin SB, Smart CD, Sandrock RW, Deahl KL, Punja ZK, Fry WE (1998) Genetic change within populations of Phytophthora infestans in the United States and Canada during 1994 to 1996: role of migration and recombination. Phytopathology 88:939-949 
Gotoh K, Akino S, Maeda A, Kondo N, Naito S, Kato M, Ogoshi A (2005) Characterization of some Asian isolates of Phytophthora infestans. Plant Pathol 54:733-739

Gur A, Zamir D (2004) Unused natural variation can lift yield barriers in plant breeding. PLoS Biol 2:e245

Hanson P, Sitathani K, Sadashiva A, Yang R-y, Graham E, Ledesma D (2007) Performance of Solanum habrochaites LA1777 introgression line hybrids for marketable tomato fruit yield in Asia. Euphytica 158:167-178

Jones J, Jones J, Stall R, Zitter TA (1991) Compendium of tomato disease. American Phytopathological Society, St. Paul, Minnesota

Kole C, Ashrafi H, Lin G, Foolad M (2006) Identification and molecular mapping of a new $\mathrm{R}$ gene, $P h-4$, conferring resistance to late blight in tomato. Solanaceae Conference, University of Wisconsin, Madison, Abstract 449

Labate JA, Grandillo S, Fulton T, Munos S, Caicedo AL, Peralta I, Ji Y, Chetelat RT, Scott JW, Gonzalo MJ, Francis D, Yang W, van der Knaap E, Baldo AM, SmithWhite B, Mueller LA, Prince JP, Blanchard NE, Storey DB, Stevens MR, Robbins MD, Wang JF, Liedl BE, O'Connell MA, Stommel JR, Aoki K, Iijima Y, Slade AJ, Hurst SR, Loeffler D, Steine MN, Vafeados D, McGuire C, Freeman C, Amen A, Goodstal J, Facciotti D, Van Eck J, Causse M (2007) Tomato. In: Labate CR et al (eds) Genome mapping, molecular breeding in plants, Vegetables, vol 5. Springer-Verlag, Berlin, Heidelberg, pp 1-125

Lecomte L, Duffé P, Buret M, Servin B, Hospital F, Causse M (2004) Marker-assisted introgression of five QTLs controlling fruit quality traits into three tomato lines revealed interactions between QTLs and genetic backgrounds. Theor Appl Genet 109:658-668

Monforte AJ, Tanksley SD (2000) Development of a set of near isogenic and backcross recombinant inbred lines containing most of the Lycopersicon hirsutum genome in a $L$ esculentum genetic background: a tool for gene mapping and gene discovery. Genome 43:803-813

Monforte AJ, Friedman E, Zamir D, Tanksley SD (2001) Comparison of a set of allelic QTL-NILs for chromosome 4 of tomato: deductions about natural variation and implications for germplasm utilization. Theor Appl Genet 102:572-590
Moreau P, Thoquet P, Olivier J, Laterrot H, Grimsley N (1998) Genetic mapping of $P h-2$, a single locus controlling partial resistance to Phytophthora infestans in tomato. Mol Plant Microbe Interact 11:259-269

Palloix A, Ayme V, Moury B (2009) Durability of plant major resistance genes to pathogens depends on the genetic background, experimental evidence and consequences for breeding strategies. New Phytol 183:190-199

Peirce LC (1971) Linkage tests with $\mathrm{Ph}$ conditioning resistance to race 0, Phytophthora infestans. Tomato Genet Coop Rep 21:30

Rousseaux M, Jones C, Adams D, Chetelat R, Bennett A, Powell A (2005) QTL analysis of fruit antioxidants in tomato using Lycopersicon pennellii introgression lines. Theor Appl Genet 111:1396-1408

Smart CD, Tanksley SD, Mayton H, Fry WE (2007) Resistance to Phytophthora infestans in Lycopersicon pennellii. Plant Dis 91:1045-1049

Stall RE, Jones JB, Minsavage GV (2009) Durability of resistance in tomato and pepper to Xanthomonads causing bacterial spot. Annu Rev Phytopathol 47:265-284

Tieman DM, Zeigler M, Schmelz EA, Taylor MG, Bliss P, Kirst M, Klee HJ (2006) Identification of loci affecting flavour volatile emissions in tomato fruits. J Exp Bot 57: 887-896

Turkensteen L (1973) Partial resistance of tomatoes against Phytophthora infestans, the late blight fungus. Dissertation, Wageningen University, The Netherlands

Vleeshouwers VGAA, van Dooijeweert W, Paul Keizer LC, Sijpkes L, Govers F, Colon LT (1999) A laboratory assay for Phytophthora infestans resistance in various Solanum species reflects the field situation. Eur J Plant Pathol 105: 241-250

Wastie R (1991) Resistance to powdery scab of seedling progenies of Solanum tuberosum. Potato Res 34:249-252

Widmark A-K, Andersson B, Cassel-Lundhagen A, Yuen MSJE (2007) Phytophthora infestans in a single field in southwest Sweden early in spring: symptoms, spatial distribution and genotypic variation. Plant Pathol 56:573-579 